2018-03

Thermally Comfortable Housing in IraqProspects of the Courtyard Pattern in Achieving Energy Efficiency

\author{
Al-Hafith, Omar \\ http://hdl.handle.net/10026.1/13176
}

10.1007/978-3-319-63709-9_69

PROCEEDINGS OF 3RD INTERNATIONAL SUSTAINABLE BUILDINGS SYMPOSIUM (ISBS

2017), VOL 1

Springer International Publishing

All content in PEARL is protected by copyright law. Author manuscripts are made available in accordance with publisher policies. Please cite only the published version using the details provided on the item record or document. In the absence of an open licence (e.g. Creative Commons), permissions for further reuse of content should be sought from the publisher or author. 


\title{
THERMALLY COMFORTABLE HOUSING IN IRAQ - PROSPECTS OF THE COURTYARD PATTERN IN ACHIEVING ENERGY EFFICIENCY
}

\author{
Mr - Omar Al-Hafith ${ }^{a}$, Dr - Satish Basavapatna ${ }^{\mathrm{b}}$, \\ Mr - Simon Bradbury ${ }^{c}$ and Prof - Pieter de Wilde ${ }^{d}$ \\ a * Plymouth University, ADA School, Plymouth,The UK, \\ omar.al-hafith@plymouth.ac.uk \\ b Plymouth University, ADA School, Plymouth, The UK \\ satish.bk@plymouth.ac.uk \\ c Plymouth University, ADA School, Plymouth, The UK, \\ simon.bradbury@plymouth.ac.uk \\ dPlymouth University, ADA School, Plymouth, The UK, \\ pieter.dewilde@plymouth.ac.uk
}

\begin{abstract}
Housing represents one of the most important needs for people. In Iraq, there are large housing problems. It is estimated that there is a shortage of around one million dwellings, which is equal to one-fourth of the total housing stock in the country. As a part of the solutions to this problem, the country needs architectural designs that satisfy three main conditions: enable an increase of the housing production, be affordable and satisfy people's residential requirements. The latter includes, for instance, providing suitable layouts, comfortable environment and the required level of privacy. Within this spectrum, this paper focuses on satisfying the need of providing a thermally comfortable indoor environment. The importance of this aspect rises from the high temperatures in Iraq during the long summer season, the unreliable electricity supply with frequent supply interruption, reducing the running costs and the need to maintain the environment at comfort conditions. The paper explores the courtyard pattern as an approach to achieve a thermally comfortable indoor environment, and studies how courtyards may be adopted within multistory residential buildings in order to reduce the costs and support the housing production. With an aim to define a proven thermally efficient design solution, this paper aims to investigate the courtyard thermal efficiency and to adopt it in generating potential efficient design solutions. It reports on an extensive literature review that investigates published scientific studies within the last ten years about the thermal efficiency of the courtyard pattern and its design features. The investigation includes exploring studies that have conducted experiments to define the thermal performance of the courtyard pattern. To propose design solutions, the paper considered the investigation's results and the main residential buildings criteria and standards. The research results define the thermal efficiency of the courtyard patterns and demonstrate the importance of adopting the courtyard pattern's design features to provide a thermally comfortable indoor environment. The paper proposes two
\end{abstract}

architectural solutions for Iraq that include adopting the courtyard pattern in multistory residential buildings.

Keywords: Affordable Housing, Courtyard residential buildings, Thermally efficient Housing, Housing in Iraq

\section{Introduction}

Satisfying the housing needs has been one of the main challenging issues around the world. Most countries have worked on having sufficient housing production and to providing decent housing conditions for people [1] However, there are many countries around the world that are still suffering from housing shortage and inappropriate housing conditions [2, 3].

In Iraq, because of prolonged war conditions since the 1980s and the current instability, there are large housing problems. The housing shortage is estimated to be around one million dwellings. This number represents $25 \%$ of the total housing stock in the country. The housing production is weak, while the financial system is inefficient. There are problems with the infrastructure services and construction materials availability. Furthermore, part of the housing stock is deteriorating. Slums are spreading in some parts of the country $[4,5,6]$. In response to these problems, various efforts have been taken to reverse the situation. Among the most important of them is the introduction of a National Housing Policy in 2010, which was prepared by the Iraqi government in cooperation with the UN. It defines the problems and proposes a general solution framework [5]. The National Housing Policy advocated proposing architectural solutions that can help to solve the problems. These proposed solutions should help to increase the housing production, provide affordable housing and at the same time satisfy the various people's residential requirements. This paper explores some ideas to propose an efficient and appropriate architectural solution for Iraq 
focusing on providing thermally comfortable indoor environment. This aspect represents one of the Iraqis' first residential priorities because of the high temperature during summer and the unreliable electricity supply.

\section{The Comfortable Indoor Environment}

Having a comfortable indoor is one of the most important priorities for people, as they spend much of their time inside buildings. There are studies that have suggested strong relationships between having a comfortable indoor environment and the health and productivity of buildings' occupants. It has been argued that adverse indoor environmental conditions may lead to a short term and long term illness [7].

There are four factors that determine the characteristics of buildings' indoor environment: Indoor air quality (IAQ), thermal comfort, acoustics and the visual features $[7,8,9]$.

- Indoor air quality (IAQ): Polluted indoor air has short term and long term negative impact on people wellbeing. It has been argued that fundamentally there are two ways to reduce or deal with indoor air pollution. The first one is through providing appropriate ventilation (fresh air supply) and the second one is by reducing the sources of pollution from inside and outside buildings $[7,8,9]$.

- Thermal comfort: Having a thermally comfortable indoor environment is also among the most important factors and may be the most sensitive one. It has a large impact on people wellbeing and productivity. Feeling thermally comfortable inside buildings is affected by several factors: air temperature, mean radiant temperature, humidity, air speed, people metabolic rate and clothing insulation. The first four factors are classified as natural factors and the other two as personal factors $[7,8,9]$.

- The Acoustic Comfort: One of the comfortable indoor environment conditions is to provide the voice privacy for the occupants and to protect them from the unwanted level of sound and noise. The appropriate characteristics of sound depend on building functions and affect occupants' productivity [7, 8, 9].

- The Visual Comfort: The other factor that affects occupants' comfort and productivity is the visual comfort. It includes, first of all, providing sufficient and appropriate natural lighting and then appropriate glare, colors and outside view $[7,8,9]$.

This paper focuses on the thermal comfort because, in Iraq, it is the most studied aspect in residential building performance studies. The reason for this is that Iraq is located in a hot arid location. Summer lasts from around seven months in which the temperature reaches more than $45^{\circ}$ [10]. The country thus is out of comfortable limits during most the year [11]. As a consequence, in a typical year like 2002 , 92\% of the generated power was used for the domestic purposes, and $63 \%$ of it was for air-conditioning during summer [12]. In a more recent study, by Hasan in 2012 , it has been stated that $60 \%$ and $70 \%$ of the total consumed energy in Iraq is used for air-conditioning during summer and winter respectively [10]. The problem becomes larger with the electricity supply frequent interruptions that have existed in Iraq since the 1990s. The nationally generated power provides only $50 \%$ of the needs $[13,14]$. Because of these conditions, there has been an especial focus on designing more thermally efficient buildings using passive systems to provide comfortable indoor environment, reduce the energy consumption [15, 16], and become less reliant on continuous supply of electricity.

\subsection{The Possible Architectural Alternatives}

There are a number of architectural archetypes that can be considered to be used. One of the main aspects of defining the possible architectural solution is to define the residential building pattern. In Iraq, there are seven possible building patterns. Four of them are single family housing and three multi-story housing (Figure1).

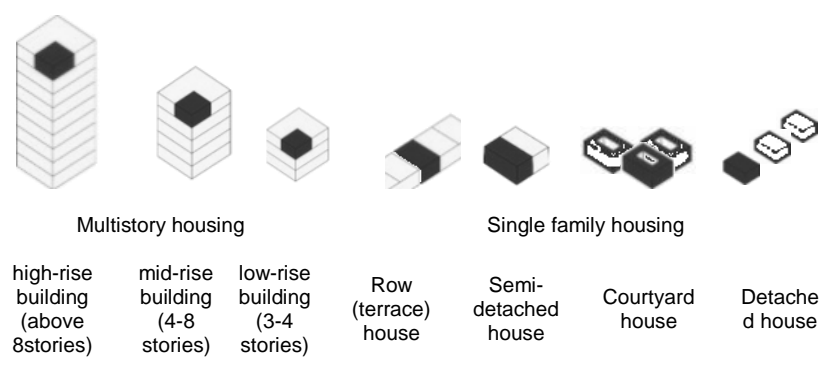

Figure 1. The residential buildings patterns in Iraq Source: the author depending on $[17,18]$.

\section{The Research Aim and Methodology}

The main aim of this study is to investigate the courtyard pattern thermal performance and to define potential thermally efficient architectural solutions for Iraq with considering the housing concerns of increasing the housing production and housing affordability.

To achieve this aim, the paper depends on exploring wideranging literature about these issues. First of all, it explored existing views on the efficiency of the seven architectural patterns in addressing the issues of increasing the production, achieving affordability and providing thermally comfortable environment. This was used to develop a concept for a thermally efficient solution that will be studied in future studies by means of building performance simulation.

\section{Defining an Efficient and Appropriate Architectural Pattern}

There are many studies that have focused on defining the architectural patterns efficiency in satisfying the various residential requirements. Table 1 summarizes findings from previous literature. It can be seen that the previous studies have identified the courtyard single family housing as an 
efficient approach to providing a comfortable indoor environment and that multistory residential buildings help to achieve affordability and support the housing production.

Table1. Previous literature evaluation of the various architectural patterns

\begin{tabular}{lccc} 
Housing & \multicolumn{3}{c}{ Evaluation aspects } \\
patterns & $\begin{array}{c}\text { Providing } \\
\text { thermal } \\
\text { comfort }\end{array}$ & $\begin{array}{c}\text { Supporting } \\
\text { the housing } \\
\text { production }\end{array}$ & $\begin{array}{c}\text { Achiving } \\
\text { affordable } \\
\text { housing }\end{array}$ \\
\hline
\end{tabular}

Detached

semi-Detached

Terrance

Courtyard

Low-Rise

Mid-Rise

High-Rise

$\underset{[19,20,21,22,23]}{\sqrt{ }}$
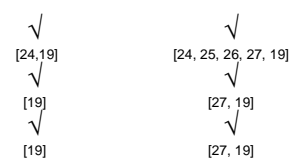

\subsection{Investigating the Courtyard Pattern Thermal Efficiency}

It has been argued by a number of studies that the courtyard pattern has been an efficient and appropriate pattern to achieve thermally comfortable environment in the hot arid zone, in which Iraq is located. Among these studies are [21, $20,28]$.

Reference [21] presented an experiment that included measuring the temperature in two models: courtyard one and non-courtyard one. The experiment showed that while the outside temperature was $35^{\circ}$ in the morning, the temperature in the courtyard house was $30^{\circ}$ and in the noncourtyard house was $40^{\circ}$. In the afternoon at 12:00, the temperature outside and in the non-courtyard pattern was around $40^{\circ}$, while it was $35^{\circ}$ in the courtyard house. In the night, the outside temperature decreased to $38^{\circ}$. The noncourtyard house tended to keep the heat inside while the courtyard one lost it. The temperature in the former was $40^{\circ}$, which is higher than outside, and in the latter, it was around $30^{\circ}$.

Reference [20] presented a courtyard house constructed in Baghdad in the 1980s, which was evaluated and won the first prize in Iraq for being the most energy efficient model in the country in 1992 (Figure2). The measurement of the temperature in the constructed house showed the efficiency of this pattern in providing thermally comfortable environment. The measurements were taken in August, which is the hottest month in Iraq. The study demonstrated that while the outside temperature was $43^{\circ}$, the temperature in the courtyard was $30.5^{\circ}$, in the ground floor rooms was $28^{\circ}$ and in a first floor room was $30^{\circ}$.
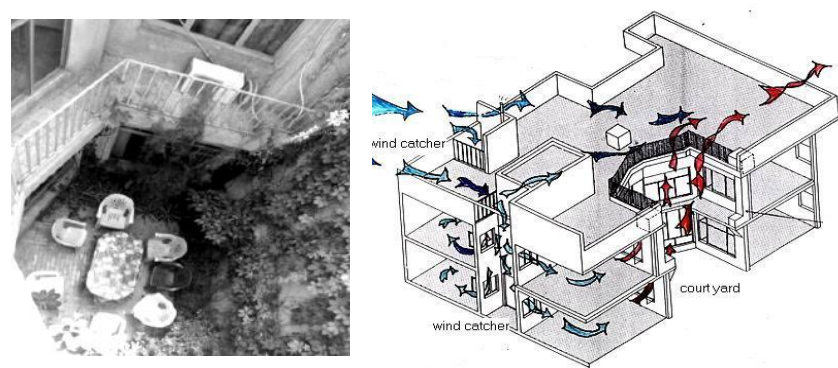

Figure 2. The courtyard house in Baghdad Source: [20]
Finally, Reference [28]presented another experiment in a courtyard house, but it was in Saudi Arabia. The experiment included measuring the temperature difference between the inside and outside in a courtyard house. It found that the courtyard pattern was able to reduce the temperature by $6.7^{\circ}$ in the courtyard and by $9.9^{\circ}$ in the rooms. Furthermore, it found the efficient performance can be supported by using a wind-catcher with a fan and sprinkling water. Using this approach, the temperature further decreased and the difference reached to $11^{\circ}$ between the outside and the courtyard and to $13^{\circ}$ between the outside and the rooms.

\subsection{Exploring the Courtyard Pattern Design Features}

The thermal efficiency of the courtyard pattern depends on systematically integrated design features and elements [20, $29,22]$. The main principals of its work include providing shading to reduce the heat gain and air movement to reduce the felt temperature. The air movement results from the pressure differences between the cold shaded areas and the hot sunny areas. In these two areas, the hot air is lighter, has less density and moves upwards to be replaced by the heavier and more density cold air. This generates low pressure area and high pressure area and leads to cause air movement [29], [30, 22]. These two principles have been used ages ago in the old traditional cities in the hot-arid climatic zone. It has been applied and supported by using a number of design strategies and features. They can be seen clearly in the old traditional courtyard neighbourhoods, but not the modern grid-iron ones [30]. Basically, there are six design elements and features in the courtyard house pattern that should be considered integrally to achieve thermally efficient housing. This paper is focusing on investigating these six elements and what can be done to support and enhance the courtyard house performance.

- Urban Fabric compactness: The first design strategy is on the macro scale. Traditionally, the courtyard houses have existed in residential neighbourhoods where houses are highly attached to each other. The circulation networks depend on organic narrow paths and relatively large private and public plazas inside and outside the buildings. This kind of compact development provides high shading for the buildings and paths, reduces the exposure to the sun and causes continuous air movement due to the pressure differences between the sunny and the shaded areas $[31,29]$. Reference [32] showed that, in Mosul city, the temperature difference between the modern grid iron 
urban fabric and the old compact traditional one is between 30 to $9^{\circ}$ (Figure 3).

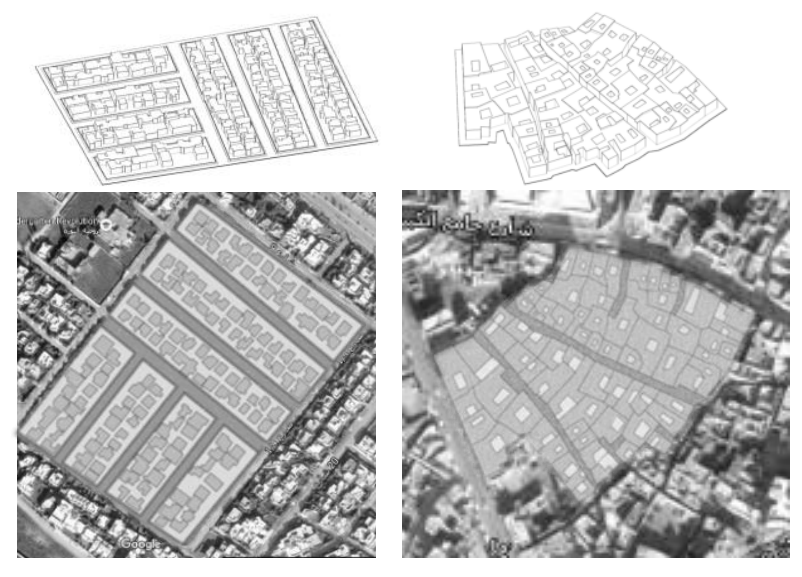

Figure 3. The compact fabric (left) and the grid iron one (right)

Source: the author depending on Google map.

- The Courtyard: it has worked on the micro scale as the main element to regulate the temperature. It works integrally with outside circulation paths depending on the pressure differences between the various areas. In the first morning hours, it is kept shaded by the surrounding walls which enable it to stay cold. At night, the surround rooms and walls radiate their stored heat to the sky through the courtyard. The hot air is replaced by cold air which helps to reduce the temperature and causes air movement in the courtyard and in the surrounding rooms (Figure 4) [21, 30, 16,33$]$.

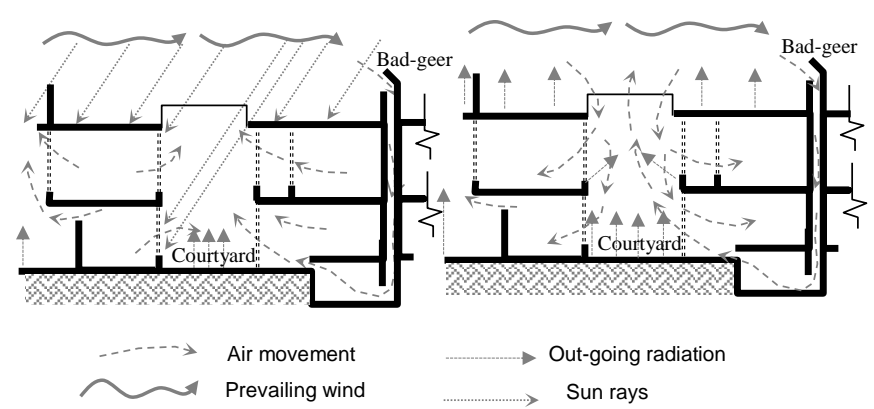

Figure 4. Air movement during day time (left) and night time (right)

Source: the author depending on [21].

- The Wind-catcher (the Bad-geer): This element works to support the courtyard in generating air movement and providing cold air for the house. It includes an upper opening on the roof and a duct that is built across the longitudinal section of the house to be opened in the basement that is opened to the courtyard through windows. The upper opening is directed towards the prevailing wind in summer to catch the cold and clear air. By being moved across the basement, the air becomes colder before reaching to the courtyard (Figure 3) [29, 16, 20, 33].

- The building envelop: It represents the main element that governs the heat exchange between the inside and the outside. Two factors affect the envelope's thermal performance: its design elements and its construction materials. Regarding the former, in the traditional courtyard houses, the enevelop elements were designed in a way that provides self-shading to the elevations. Traditionally, this has been achieved through the stone or brick ornamental details, the rough surfaces and some projected element. In addition to that, there has been no opening or small ones to provide privacy and reduce the crossed sun rays. Concerning the latter factor, the outside walls have been constructed using traditional materials like stone or mud brick with a thinness that ranges between 50 to 75 centimeters. These construction materials with this thickness delay the heat transfer and increase the thermal insulation $[30,16,21]$.

- The Mashrabia (The Shanshool) : It is a projected spatial element to the outside on the first floor that has different functions including supporting the thermal performance of the courtyard house. It is mainly an ornamentally latticed opening to the outside alley. This composition enables it to provide opening to the outside with keeping the inside privacy, as it is designed in a way that provides the ability to see from the inside but not the inverse. Thermally, it provides shading for the outside and the inside and keeps air movement through it. Water pitchers are used to be put inside to cool the move air through it (Figure 5) [30, 16, 22, 29].

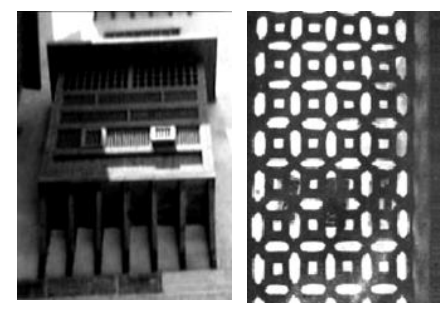

Figure 5. The Mashrabia details and location Source: $[29,30]$

- The water elements and planting: Water has been used to increase the humidity and mitigate the temperature. It helps through its evaporation in reducing air temperature. In addition to that, passing the moving air over a water surface helps cooling it. Because of this, several water elements have been used to increase the thermal performance of the courtyard house. Among the most used elements are the fountains, which have been built in the middle of the courtyard, and the Salsabeel, which is a marble surface with water passing over it in front of the wind-catcher openings. Planting have been used also in the courtyard to increase the humidity and reduce the temperature [30, $16,20]$. 
- The basement: It is a space built to be under the ground. The aim of this space is to provide thermally comfortable space in summer benefiting from being surrounded by soil. This help to neutralize the impact of outside temperature on the inside one. It also works with the wind-catcher to cool the crossed air before reaching to the courtyard space [29, 21, 30]. Reference [21] presented a study that showed that in summer when the outside temperature was around $45^{\circ}$, in the basement it was around $25^{\circ}$

\subsection{Other Discussion points: Courtyard Other Advantages and the Disadvantages}

In addition to its efficient thermal performance, there are other advantages of adopting the courtyard pattern. Among them, is that it has been efficient in providing natural lighting and ventilation [34, 28]. It has been efficient in satisfying the social and cultural requirement of providing high privacy degree by being opened to the inside and closed to the outside [28]. Finally, its design provides a flexible internal layout that suits a variety of functions [19].

However, the courtyard pattern has been gradually abandoned in all of the Iraqi cities since the 1950s. Houses styles have changed from being according to the courtyard pattern with limited opening to the outside to the current outside opening modern forms [35, 36]. This changing in the adopted architectural style has been affected by the country general conditions, which for instance included the political and social changes that accompanied the ending of the Ottoman Empire and the British occupation of Iraq in the beginning of the 20th century. In addition to that, it has been affected by the architectural trends around the world, the local architects' views, the social preferences and the developments in the construction and materials industry $[37,38,39]$.

In addition to these factors, there are some environmental disadvantages associated with courtyard pattern that may affect people preference for the modern houses styles. Among these disadvantages, is that the courtyard does not provide thermal comfort during periods of the year. The passive design strategies sometimes become not efficient to deal with certain degrees of hot or cold weather conditions, spatially in the winter when it becomes very difficult to warm the spaces. The open courtyard is also not efficient to deal with the rain storms in winter or dust storms in summer when the atmosphere becomes breathless. Natural lighting doesn't reach the courtyard and the surrounded rooms sufficiently in winter. Another point is that it becomes so moisture in winter in some spaces, especially in the basement $[22,33]$.

\subsection{Improving the courtyard pattern performance}

To support the courtyard house performance and to overcome its disadvantages, there are some studies that have focused on exploring strategies to enhance this performance. Reference [22] presented the use of mechanical heating and cooling systems and artificial lighting to improve the house's performance. Reference [28] argued that by using simple fans in the wind-catcher the thermal performance of the courtyard house increases. It showed this through an experiment in which the temperature decreased $3.5^{\circ}$ and $5.5^{\circ}$ in the courtyard and the surrounded rooms respectively more than if it is used without fans. Reference [20] showed a developed model of the courtyard house pattern. It included surrounding the courtyard with glass walls to neutralize the unwanted climatic conditions when it needed with getting the benefits of the courtyard when it is possible.

\section{Proposing an Architectural Solution for Iraq}

After exploring the courtyard pattern's efficiency, its main design features, its weak points and some of the ideas to enhance its performance, the paper proposes two architectural design solutions for Iraq. Both of them include using the courtyard pattern within multistory residential buildings. The paper suggests this kind of solutions as an approach to achieve affordable and efficient housing production and at the same time provide a thermally comfortable environment. It proposes these two solutions to be developed and tested in future studies to determining their potential environmental performance in addition to determine their efficiency in addressing the other residential requirements.

The proposed models in (Figure 6) and (Figure 7) are three stories buildings. The first one includes one bedroom flats, two bedrooms flats and three bedrooms flats and the second one only one and two bedrooms flats. In both of the proposed solutions, each flat has its own private courtyard which is surrounded by the various living spaces. A windcatcher is also provided for each flat. The courtyards are surrounded by glassed walls to neutralize the impact of the undesirable weather conditions and benefits of their efficient performance when it is possible. The paper also supports using some of the modern mechanical air-conditioning devices to support the courtyard when it cannot provide the required conditions.

Building on the explored literature, the paper suggests the potential air movement that will occur in the proposed solutions. As it is shown in (Figure.6) and (Figure.7), the wind-catcher will catch the air, with considering directing its upper opening to the correct direction, and directing it to the courtyard from which it will be distributed to the surrounded spaces. A water surface can be put in the bottom of the wind catcher to cool the air before reaching the courtyard.

In designing the two proposed solutions, the paper considers providing other main design requirements, which include providing privacy $[40,41]$, appropriate and standard layouts and areas [42, 43]. 


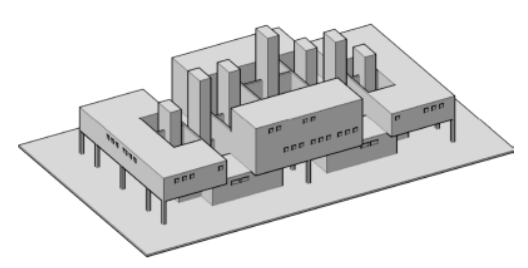

The building Isometric

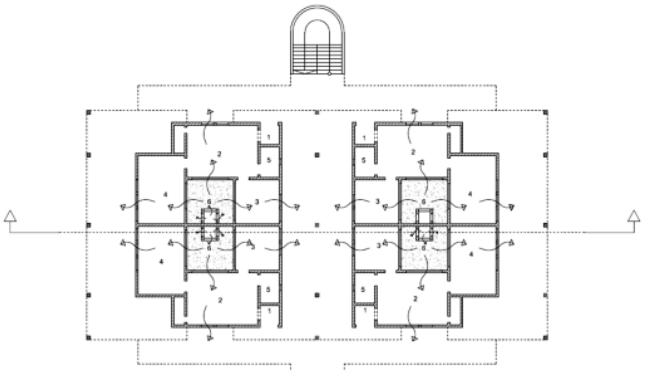

筆基

The ground floor

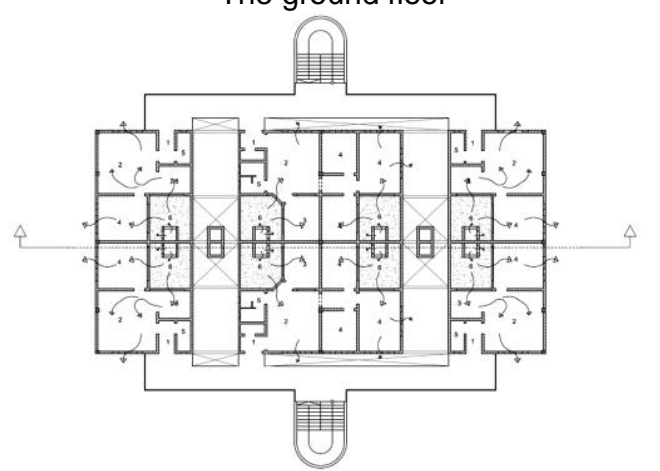

The first floor

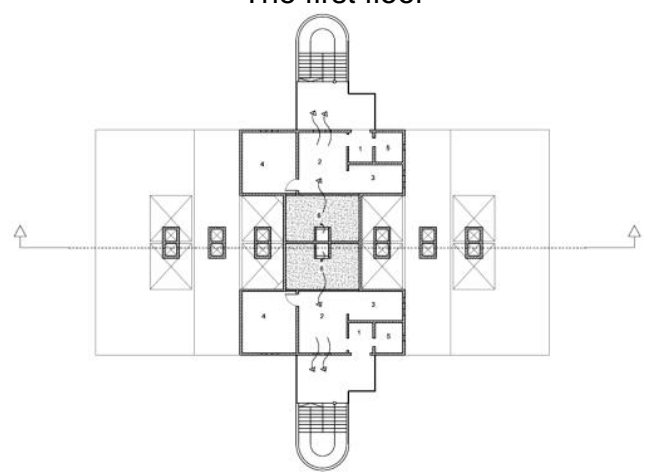

The second floor

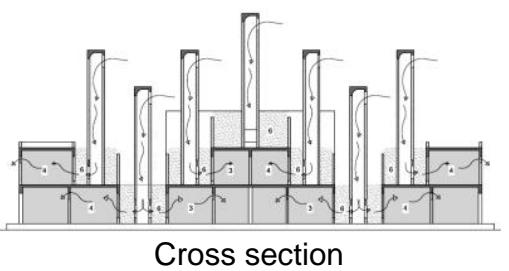

Figure6. Solution 1 - A three stories residential building 1. Entrance, 2. Living room , 3. Kitchen 4 , Bedroom 5, Bath \& WC, 6. The courtyard

The source: The Author
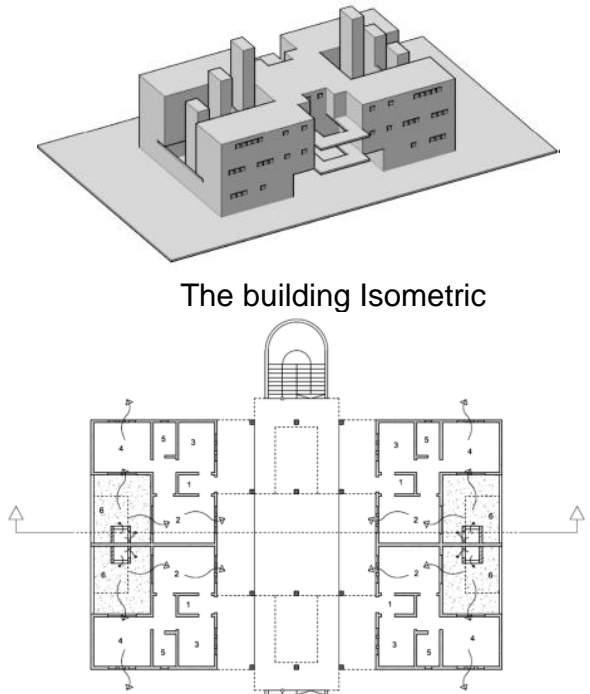

(3)

The ground floor

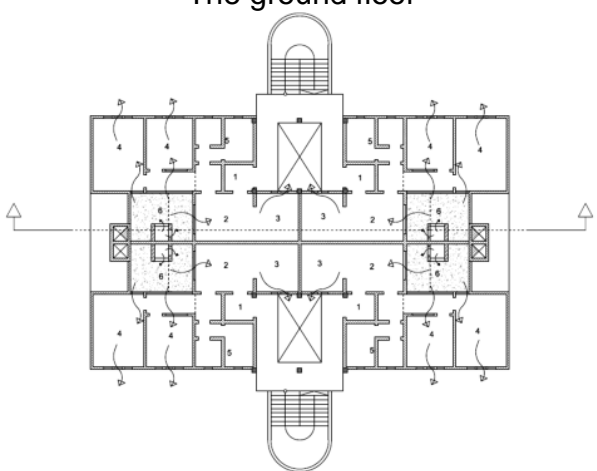

The first floor

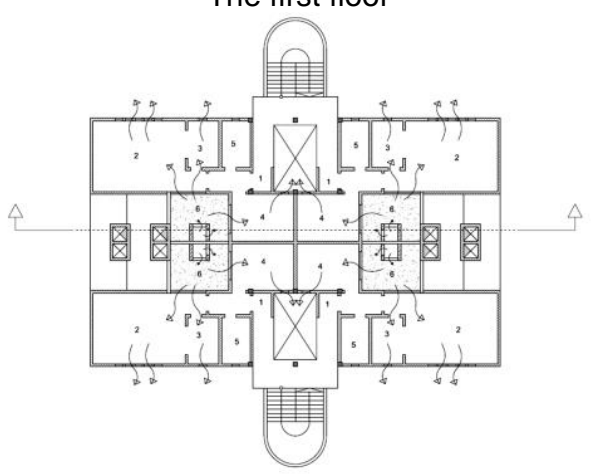

The second floor

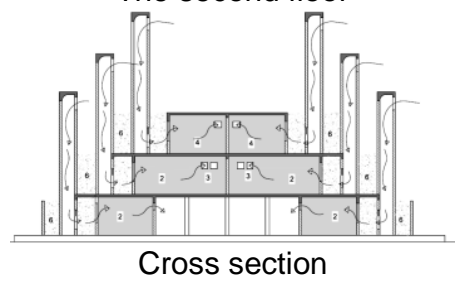

Figure 7. Solution 2- A three stories residential building 1. Entrance, 2. Living room , 3. Kitchen , 4. Bedroom , 5. Bath \& WC , 6. The courtyard

The source: The Author 


\section{Conclusions and Discussion}

This paper reports on an investigation of the use of the courtyard pattern in the context of multi-storey residential buildings in Iraq.

Previous work suggests that the courtyard pattern can be used as an efficient solution to provide a thermally comfortable indoor environment. However, the designs should incorporate all of the integrated design features and strategies to have an efficient solution. This implied using the courtyard element with other supporting elements including the wind-catchers, the mashrabia and the water elements in a compact urban fabric. Using all of these elements integrally is vital to activate and support the two main principles of courtyard performance: shading and natural ventilation

The paper also explores the prospects of developing the courtyard house pattern and enhances its performance by using modern artificial technologies that might provide more control on the climatic conditions inside the house. This includes using mechanical ventilation and lighting and surrounding the courtyard with glass walls to neutralize unwanted climatic conditions.

Finally, the paper investigates possibilities for using the courtyard pattern in modern multi-storey residential buildings. It suggests two design solutions that adopt the courtyard pattern in three stories residential buildings. They supposed to provide a thermally comfortable environment and at the same time support increasing the housing production and providing affordable housing.

The paper recommends conducting studies that focus on testing and determining this kind of design solutions performance from different aspects. This might include conducting simulation studies to test and determine their environmental performance and energy consumption with considering the impact of their various design features. It might also include conducting surveys and interviews with public people and experts in the housing sector to determine the applicability and acceptability of this kind of design solutions and the possible ways to develop it.

\section{Acknowledgements}

This paper has been conducted within an ongoing PhD study fully sponsored by (HCED) in Iraq .

\section{References}

[1] UN-HABITAT, "Issue Paper on Housing," UNHABITAT, New York, 2015.

[2] UN-HABITAT, Sustainable Housing for Sustainable Cities , A policy framework for developing cities, Nairobi: UN-HABITAT, 2012.

[3] UN-HABITAT, "HABITAT III issue paper : Informal settlements," UN-HABITAT, New York, 2015 (b).

[4] A. Al-Saadi and R. Al-Masodi, "Housing Shortage in Iraq (Its indications and Confrontation Strategies)," AlAmeed, vol. 3, pp. 368-415, 2012.
[5] Iraqi Ministry of Construction and Housing, "Iraq National Housing Policy," Iraqi Ministry of Housing and Construction, Baghdad, 2010.

[6] PADCO, "Iraq Housiing Market Study," 2006. [Online]. Available: http://www.basrahexpo.com. [Accessed 47 2015].

[7] Y. Al horr, M. Arif, M. Katafygiotou, A. Mazroei, A. Kaushik and E. Elsarrag, "Impact of indoor environmental quality on occupant well-being and comfort: A review of the literature," International Journal of Sustainable Built Environment, vol. 5, no. 1, pp. 1-11, 2016.

[8] M. Frontczak and P. Wargocki, "Literature survey on how different factors influence human comfort in indoor environments," Building and Environment, vol. 46, no. 4, p. 922-937, 2011.

[9] "ISHRAE," 8 2015. [Online]. Available: http://ishrae.in. [Accessed 38 2016].

[10] A. Hasan, "Simple roofing system suitable for buildings in hot climate and it's effect on energy conservation (Experimental study)," Iraqi Journal of Civil Engineering, vol. 10, no. 1, pp. 1-13, 2016.

[11] M. H. Al-Jawadi and H. A. Al-Singary, "Climatic control indices in properties of forming the urban residential façade," AL Rafdain Engineering Journal, vol. 18, no. 4, pp. 80-86, 2010.

[12] A. A. Hasan, "The Effect Of Changing Iraqi Residence Building Orientation, Materials And It's Construction Position On Energy Consumption," Engineering \& Technology Journal, vol. 26, no. 12, pp. 473-483, 2008.

[13] O. A. Al-juboori, "Conditions for Applying Public Private Partnership (PPP) in Iraq Infrastructure Projects Successfully - Dissertaion," Technische Universitat Munchen, Munchen - Germany, 2015.

[14] UNDP - Iraq, "Evaluation of Enabling policy framework for rapid economic recovery, inclusive and diversified growth and private sector development," UN, 2012.

[15] B. E. Yadco, "The idea climatic shape of detached in the hot arid regions," The iraqi journal of architecture, vol. 7, pp. 132-142, 2004.

[16] G. B. Hameed, "The impact of climate of the architectural form," Journal of Engineering and Development, vol. 14, no. 3, pp. 43-54, 2010.

[17] S. Davis, The Form of housing, USA: Van Nostrand Reinhold Ltd., 1977.

[18] State Commission for Housing, "Urban housing standards manual," 10 2010. [Online]. Available: http://investpromo.gov.iq/wpcontent/uploads/2013/04/URBAN-HOUSINGSTANDARDS.pdf. [Accessed 44 2016].

[19] A. H. Al-Jameel and O. A. Al-Hafith, "Investing the Concept of Courtyard for Sustainable Adaptable Multifamily Housing," American Transactions on Engineering \& Applied Sciences, vol. 1, no. 3, pp. 319$334,2012$.

[20] M. H. Al Jawadi, "Model of house design reponsive to hot-dry climate," Int. Journal for Housing Science, vol. 35, no. 3, pp. 171-183, 2011.

[21] M. I. Mohammed, "The planning and design approaches to achieve the traditional principles of sustainability in the local modern housing 
architecture," Journal of Engineering, vol. 16, no. 4, pp. 1034-1061, 2010.

[22] R. Agha, "Traditional Environmental Performance: The Impact of Active Systems upon the Courtyard House Type, Iraq," Journal of Sustainable Development, vol. 8, no. 8, pp. 28-41, 2015.

[23] E. Kareem, "Studying the impact of the courtyard in dealing with climate and social conditions of Arabia residential units," Journal of Babylon University, vol. 17, no. 1, pp. 446-455, 2009.

[24] B. A. -H. Al-Hussaini, "Achieving the residential sufficiency by effective updating the master plan and satisfy the housing need in Al-Haidariya area," AlGharee for Economics and Administration Sciences, vol. 11, no. 34, pp. 239-279, 2015.

[25] K. . J. M. Al- Korayshi, Housing Planning in Iraq according to Cost and Social Benefit - Case Study : Baghdad City (PhD disseration), Baghdad: Baghdad University, 2006.

[26] L. T. Mula-Huish and I. K. Jumaa, "A number of alternatives for the preferred housing in Baghdad," Journal of Engineering, vol. 14, no. 3, pp. 379-389, 2008.

[27] T. F. Ibrahem, "The role of neighbourhood on formulating sustainable residential complexes in Iraq : The case studies are the Sabe Abkar housing project and 28 Nissan housing project in Baghdad," Journal of the planner and development, no. 26, pp. 1-23, 2012.

[28] B. Edwards, M. Sibely, M. Hakmi and P. Land, courtyard house - past - present and future, U.S.A.: Taylor \& Francis, 2006.

[29] B. R. Shaheen and S. L. Ahmad, "The social environmental and aesthetic integration in the designing of the multifamily housing developments: Evaluating the Iraqi experience," Journal of Engineering, vol. 17, no. 4, pp. 156-176, 2011.

[30] T. H. Ali and B. . R. Shaheen, "The Climatic Considerations for Planning \& Architecture of the Traditional Arab City "Old City of Mosul, as a Model"," Al-Rafidain Engineering, vol. 21, no. 1, pp. 20-32, 2013.

[31] T. H. Ali, "The possible ways to use the planning and architectural techniques to rationalize the consumption of electric power," Journal of the planner and development, no. 25, pp. 135-157, 2012.

[32] T. H. Ali, The Environmental reference in the Arab city (Unpublished PhD thesis), Baghdad: Baghdad University, 2007.

[33] L. José , Bioclimatic Devices of Nasrid Domestic Buildings, USA: Aga Khan Program for Islamic Architecture at The Massachusetts Institute of Technology - MIT, 2012.

[34] Q. Chen, Y. Feng and G. Wang, "Healthy Buildings Have Existed in China Since Ancient Times," Indoor and Built Environment, vol. 3, no. Sage Publication, pp. 79-86, May 1997.

[35] S. A. Abbas, "The Architectural Development in Baghdad's house's elevations"an analytical study in Baghdad's house's elevations at twentieth century," Engineering \& Technology Journal, vol. 27, no. 7, pp. 234-249, 2009.

[36] A. K. Al-Sadkhan and H. Alaa-Eledin, "It transformations the residential architecture of Iraq in the first of the twenty-first century decade," Journal of Engineering, vol. 19, no. 2, pp. 1-18, 2013.

[37] I. J. Al-yousif and A. S. Khalaf, "Consumption in Architecture : Study in the formulas for dealing with consumption in the local architecture," The iraqi journal of architecture, vol. 8, no. 25-26, pp. 158-181, 2012.

[38] N. A. Mohammed, "The traditional house between orginality and modernity," Journal of Engineering and Development, vol. 16, no. 4, pp. 13-32, 2012.

[39] . G. M. Razzouqi, "The Relationship between Identity and Creativity in Architecture Analytical View According to the Demand of Accquiring the Identity in Contemporary Iraqi Architecture," Journal of Engineering, vol. 11, no. 1, pp. 9-28, 2005.

[40] W. Shukur and S. Hameed, "The privacy and the isolation in the residential envrionment," The iraqi journal of architecture, no. 7, pp. 176-196, 2004

[41] M. Al-Jawadi and A. Noori, "The impact of the design solution in the structural barriers in the provision of visual blocking in residential buildings," The iraqi journal of architecture, no. 4, pp. 70-80, 2001

[42] A. . A. Abod, A. M. Hussain and A. M. Al-khafaji, "Building performance : A study for evaluate prefabricated residational buildings performance," The iraqi journal of architecture, vol. 7, no. 22, pp. 255-277, 2011

[43] State Commission for Housing, "Urban housing standards manual," 10 2010. [Online]. Available: http://investpromo.gov.iq [Accessed 44 2016] 